\title{
Effects of preparation conditions on the membrane properties of alumina-coated silicon carbide supports
}

\author{
Jang-Hoon HA ${ }^{1, \dagger}$, Sujin LEE ${ }^{1}$, Syed Zaighum Abbas BUKHARI ${ }^{1}$, Jongman LEE $^{\mathbf{1}}$, \\ In-Hyuck SONG ${ }^{1}$, Seung Jun LEE $^{2}$ and Jaeho CHOI ${ }^{2}$ \\ ${ }^{1}$ Powder and Ceramics Division, Korea Institute of Materials Science, 797 Changwondaero, Seongsan-gu, \\ Changwon, Gyeongnam 51508, Republic of Korea \\ ${ }^{2}$ Agency for Defense Development, 160 Bugyuseong-daero 488beon-gil, Yuseong-gu, Daejeon 34060, Republic of Korea
}

\begin{abstract}
Porous ceramic membranes have received increasing attention for decades. Due to their excellent thermal and chemical properties. Because their pore sizes of as-sintered silicon carbide supports are within the microfiltration range, silicon carbide membranes have been actively investigated by many researchers and industries. For example, silicon carbide supports by themselves (average pore size of 1-10 $\mu \mathrm{m}$ ) and microfiltration layer-coated silicon carbide supports (average pore size of 0.1-1 $\mu \mathrm{m}$ ) can be easily prepared. However, there is insufficient data concerning the combination of ultrafiltration layer-coated silicon carbide supports (average pore size of below $0.1 \mu \mathrm{m}$ ). Therefore, the authors first prepared typical microfiltration layer-coated silicon carbide supports, and then deposited ultrafiltration layers on them. Furthermore, the authors characterized the membrane properties of the ultrafiltration layer-coated silicon carbide supports. In addition, the possibility of reducing the average pore size of microfiltration layer-coated silicon carbide supports below $0.1 \mu \mathrm{m}$ was investigated, and improving the water permeability of ultrafiltration layer-coated silicon carbide supports by controlling processing conditions such as the heat-treatment temperature, dip-coating conditions, and composition of the alumina coating slurry was explored.

@2018 The Ceramic Society of Japan. All rights reserved.
\end{abstract}

Key-words : Nano-sized alumina coating, Silicon carbide support, Pore characteristics, Ultrafiltration

[Received May 31, 2018; Accepted July 18, 2018]

\section{Introduction}

Recently, porous ceramics have attracted significant interest $^{1)}$ due to their numerous advantages, including thermal, mechanical, and chemical stability, low density, ${ }^{2)}$ low thermal conductivity, ${ }^{3), 4)}$ and low dielectric constants. 5) The authors recognized that porous ceramic membranes ${ }^{6), 7)}$ are some of the most feasible applications of porous ceramics because, for example, in the textile industry, polymeric membranes are not appropriate for use under highly acidic/basic conditions or filtering hightemperature waste water. ${ }^{8), 9)}$ In the food industry, the major drawback of polymeric membranes is their low corrosion resistance in acidic media, and hence these membranes possess short life-cycle times, especially for juice processing applications. ${ }^{10)}$ In the oil industry, the hydrophilicity of porous ceramic membranes discourages fouling with organic matter and high mechanical stability during the filtration of abrasive media. ${ }^{11)}$

However, since the fabrication costs of typical porous ceramic membranes are much higher than those of typical porous polymer membranes, the potential for actual

Corresponding author: J.-H. Ha; E-mail: hjhoon@kims. re.kr industrial applications of porous ceramic membranes is extremely low. Therefore, it is very important to attempt to control the membrane properties of porous ceramic membranes, such as their average pore size, mechanical strength, coating layer thickness, and water permeability, while lowering their fabrication costs.

The authors previously analyzed low-cost membranes for microfiltration to reduce the cost of porous ceramic membranes. The first attempt involved diatomite-based supports for microfiltration, ${ }^{12)-23)}$ because the authors had extensive experience with diatomite for fabricating humidity-controlling tile. ${ }^{24)}$ Moreover, diatomite is an inexpensive, raw, and silica-based material, therefore, its processing would require relatively lower sintering temperatures and would involve less expenses compared to alumina-based materials.

A second attempt involved using pyrophyllite-based supports for microfiltration. ${ }^{25)-27)}$ This time, the authors tried to reduce the fabrication cost to a minimum. Pyrophyllite, which is abundant in the Republic of Korea, is an exceptionally inexpensive, raw, and silica-based material. However, because pyrophyllite particles are plate-like, the membrane properties (especially the permeability) of pyrophyllite-based supports were inferior.

The latest attempt concerned silicon carbide-based sup- 
ports for microfiltration. ${ }^{28), 29)}$ Recently, the authors successfully prepared silicon-carbide supports at low temperature, ${ }^{30)}$ therefore, these became candidates for manufacturing low-cost porous ceramic membranes.

Of the three above-mentioned types of low-cost porous ceramic membranes, diatomite and pyrophyllite-based supports were based on natural materials. Therefore, due to the insurmountable limitations of natural materials, such as high impurities, variable composition and particle size, and low mechanical strength (because the majority phase is inherently silicon oxide), diatomite and pyrophyllitebased supports were considered more appropriate for microfiltration applications. Further processing costs, such as depositing ultrafiltration layers, may severely impact the advantages of using low-cost natural materials.

The authors investigated ultrafiltration layer-coated silicon carbide supports, because silicon carbide supports exhibit good anti-fouling properties, which are due to their exceptionally high hydrophilicity, ${ }^{31), 32)}$ and have good abrasion resistance. ${ }^{33)}$ Previous studies have extensively investigated silicon carbide supports for microfiltration, 29),31),34),35) microfiltration layer-coated silicon carbide supports with silicon carbide ${ }^{32), 36), 37)}$ and alumina coating layers. ${ }^{28)}$ However, few studies have investigated ultrafiltration layer-coated silicon carbide supports with alumina $^{38)}$ and silicon carbide coating layers. ${ }^{39)}$

In this study, the authors discussed tailoring membrane properties (alumina coating layer thickness and average pore size) of an ultrafiltration layer-coated silicon carbide support by controlling processing parameters such as the dip-coating conditions, specimen size of the silicon carbide support, number of coatings, and coating slurry compositions (content of alumina and additives).

\section{Materials and methods}

\subsection{Preparation of silicon carbide supports}

To prepare a silicon carbide support, silicon carbide $(\alpha$ silicon carbide, average particle size of $6.70 \mu \mathrm{m}$, Dalian Zhengxing Abrasive Co. Ltd., China) was used. Kaolin (Sigma-Aldrich, USA) was mixed as a sintering additive for the fabrication of "clay-bonded" silicon carbide supports. Conventional sintering of a silicon carbide support requires a temperature of $2373 \mathrm{~K}$ due to the strong covalent Si-C bonds. ${ }^{33)}$ However, adding kaolin allows for the formation of clay-bonded silicon carbide at the relatively low temperature of $1673 \mathrm{~K}$, therefore reducing the manufacturing cost of silicon carbide supports. We provided a detailed explanation of the preparation and characteristics of silicon carbide supports in our previous studies. ${ }^{29), 30), 36)}$ It should be mentioned that each silicon carbide support layer was extruded as a flat sheet tube $(50 \times 4 \times 200 \mathrm{~mm})$ with 16 inner holes $(2 \times 2 \mathrm{~mm})$, and sintered at $1673 \mathrm{~K}$ for $1 \mathrm{~h}$ (with binder burned-out at $673 \mathrm{~K}$ for $1 \mathrm{~h}$ ).

\subsection{Deposition of microfiltration layer on as- prepared silicon carbide support}

To deposit a microfiltration (alumina coating) layer on an as-prepared silicon carbide support, a dip-coating machine (table-top dip-coater, E-flex, Korea) was used. We included a detailed explanation of the preparation and characteristics of the microfiltration layer-coated silicon carbide supports in a previous study. ${ }^{28)}$

\subsection{Deposition of ultrafiltration layer on microfiltration layer-coated silicon car- bide support}

To deposit an ultrafiltration (alumina coating) layer on a microfiltration layer-coated (alumina coating layer) silicon carbide support, a dip-coating machine (table-top dipcoater, E-flex, Korea) was used. The average particle size of the alumina raw material used in the microfiltration layer coating process was in the sub-micron range $(0.27$ $\mu \mathrm{m})$. However, the average particle size of alumina (nano alumina, Sigma-Aldrich, USA) used for the ultrafiltration layer coating process was in the nano-range $(50 \mathrm{~nm})$.

To prepare the alumina coating slurry for ultrafiltration coating, 2-propanol (Sigma-Aldrich, USA), distilled water, and polyvinyl alcohol (PVA 500, organic binder, Junsei Chemical, Japan) were mixed and ball-milled using alumina balls for $4 \mathrm{~h}$. A microfiltration layer-coated (alumina coating layer) silicon carbide support was dip-coated for 1-10 s. Subsequently, the support was retracted from the dip-coating machine at a withdrawal rate of $1-10 \mathrm{~mm} / \mathrm{s}$. The ultrafiltration layer-coated silicon carbide support was dried at $298 \mathrm{~K}$ for $24 \mathrm{~h}$, and then heat treated at 1073$1573 \mathrm{~K}$. It should be noted that the ultrafiltration layer was coated only on the external surface of the microfiltration layer-coated silicon carbide support.

Hereinafter, the silicon carbide support that was alumina-coated and heat treated at $1573 \mathrm{~K}$ for $1 \mathrm{~h}$ for microfiltration will be referred to as the microfiltration layer-coated silicon carbide support and the silicon carbide support that was alumina-coated and heat treated at $1573 \mathrm{~K}$ for $1 \mathrm{~h}$ for microfiltration and was alumina-coated and heat treated again at $1273 \mathrm{~K}$ for $1 \mathrm{~h}$ for ultrafiltration will be referred to as the ultrafiltration layer-coated silicon carbide support.

\subsection{Characterizations of ultrafiltration layer- coated silicon carbide support}

The microstructure and pore characteristics of the ultrafiltration layer-coated silicon carbide support were analyzed using scanning electron microscopy (SEM) (JSM5800, JEOL, Japan) and mercury porosimetry (Autopore IV 9510, Micromeritics, USA). The flexural strengths of the silicon carbide, diatomite, pyrophyllite support, and alumina supports were measured using an Instron 4206 (Instron, USA) universal testing machine. For comparison, alumina and pyrophyllite supports were prepared in using the previously reported method. ${ }^{26), 27), 40)}$ For the flexural strength measurement, at least five supports from each sample were machined to the $3 \times 4 \times 25 \mathrm{~mm}$ size and measured on conventional four-point fixtures with $20 \mathrm{~mm}$ outer spans.

The pure water permeability of the silicon carbide supports was analyzed using a dead-end microfiltration mea- 
surement system (MTS2000, Sam Bo Scientific, Korea) equipped with typical particle counters (PAMAS-4132, PAMAS, Germany). The operating trans-membrane pressure was maintained at 2.0 bar as according to the previously reported method. ${ }^{26), 27), 40)}$

\section{Results and discussion}

As already mentioned, silicon carbide supports have significant potential for industrial applications, because they have low sintering temperatures $(1673 \mathrm{~K}$, which is applicable only to clay-bonded silicon carbide), adequate flexural strength $(41.5 \mathrm{MPa})$ and can be manufactured using relatively inexpensive raw materials (considering that silicon carbide is not a natural material). Figure 1 shows the average pore size and flexural strength of the silicon carbide, diatomite, pyrophyllite, and alumina supports. It should be noted that the flexural strength of the silicon carbide support $(41.5 \mathrm{MPa})$ was significantly higher than that of natural material-based supports such as diatomite $(28.1 \mathrm{MPa})$ and pyrophyllite $(16.3 \mathrm{MPa})$, although still lower than that of alumina (77.9 MPa).

As can be seen in Fig. 1, the silicon carbide support exhibited appropriate flexural strength. Permeability and strength, which are strongly affected by both porosity and pore structure, are inherently in a trade-off relationship. Considering the authors' extensive research experience regarding natural materials-based supports, such as diatomite and pyrophyllite, to overcome the drawbacks of natural materials-based supports (low strength to fabricate a unit, build a module, and operate a system), permeability had to be sacrificed to increase the strength. However, strength is not a concern for silicon carbide supports.

Furthermore, Fig. 1 shows the surmountable average pore size disadvantage of the silicon carbide support (1.80

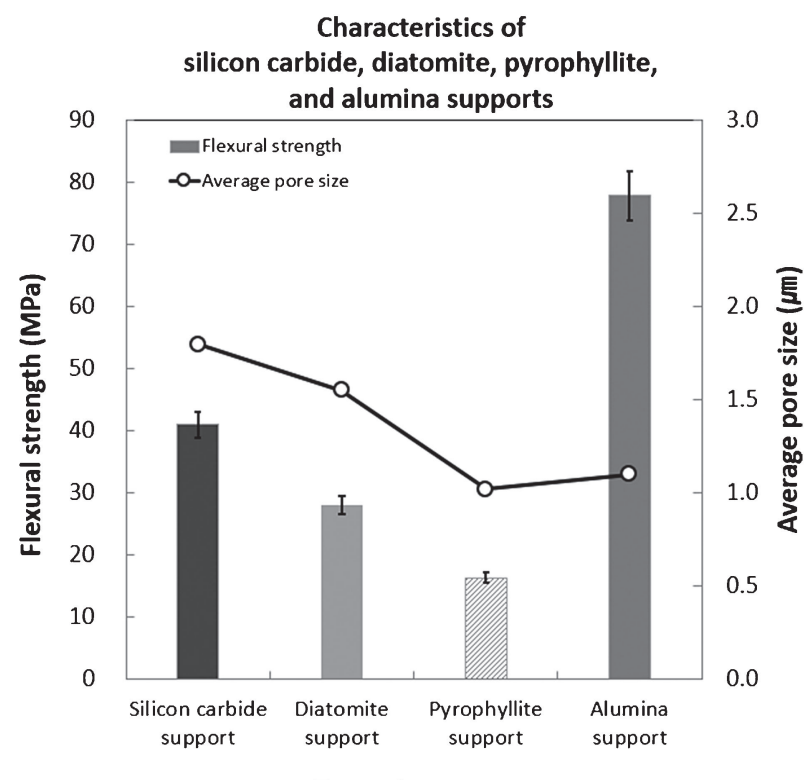

Type of support

Fig. 1. Flexural strengths and average pore sizes of a silicon carbide support sintered at $1673 \mathrm{~K}$ for $1 \mathrm{~h}$, a diatomite support sintered at $1473 \mathrm{~K}$ for $1 \mathrm{~h}$, a pyrophyllite support sintered at $1473 \mathrm{~K}$ for $1 \mathrm{~h}$, and an alumina support sintered at $1873 \mathrm{~K}$ for $1 \mathrm{~h}$. $\mu \mathrm{m})$. The pores of the silicon carbide support were approximately two times larger than those of the alumina support $(1.10 \mu \mathrm{m})$. As the average pore size difference between the coating layer and support increased, it was more difficult to obtain a rigid and thin coating layer, because, some particles in the coating layer should be suspended above the pores of the support. To facilitate their uses in ultrafiltration applications, the average pore size of silicon carbide supports must be lower than $0.1 \mu \mathrm{m}$.

When fabricating silicon carbide supports, their average pore size is limited by the relatively irregular and large raw original silicon carbide particles. Therefore, alumina particles (AKP-30, average particle size of $0.27 \mu \mathrm{m}$ ) were coated as a microfiltration layer to decrease the average pore size of the silicon carbide supports below $0.1 \mu \mathrm{m}$, thus rendering them appropriate for microfiltration. The feasibility of silicon carbide supports after appropriate coating layer deposition such as microfiltration and ultrafiltration layers as substitutes for typical alumina supports was dependent on reducing their pore sizes to the average pore size range required for microfiltration and ultrafiltration, respectively.

Therefore, in this study, finer alumina particles (nano alumina, average particle size of $50 \mathrm{~nm}$ ) were applied as an ultrafiltration layer coating to decrease the average pore size of the microfiltration layer-coated silicon carbide supports (which were already decreased to $0.1 \mu \mathrm{m}$ ) below $0.1 \mu \mathrm{m}$.

In a previous report, ${ }^{28)}$ the properties of microfiltration layer-coated and as-prepared silicon carbide supports were examined using X-ray diffraction (XRD). Both silicon carbide $(\mathrm{SiC})$ and silicon dioxide $\left(\mathrm{SiO}_{2}\right)$ (cristobalite) peaks appeared in the XRD pattern of the silicon carbide supports. Therefore $\mathrm{SiC}$ (matrix phase) and $\mathrm{SiO}_{2}$ (bonding phase) were the major phases in silicon carbide supports after sintering at $1673 \mathrm{~K}$ for $1 \mathrm{~h}$. The XRD pattern of the microfiltration layer-coated silicon carbide support presented a combination of peaks for silicon carbide and alumina, which confirmed that no undesirable and uncontrollable phase transformation occurred between the silicon carbide support and alumina coating layer.

Conventionally, the coating layer thickness strongly depends on the support dipping time ${ }^{41)}$ and withdrawal speed of the dip-coating process. The microfiltration layercoated silicon carbide supports were fabricated using the dip-coating machine. The support dipping time varied from 1 to $10 \mathrm{~s}$, and the support withdrawal speed was controlled from 1 to $10 \mathrm{~mm} / \mathrm{s}$. After the microfiltration layer coating process, heat treatments were performed in the $1473-1673 \mathrm{~K}$ range for $1 \mathrm{~h}$. In one of the authors' previous studies included a detailed explanation on the principles and important factors of the dip-coating process of the microfiltration layer-coated silicon carbide supports. The same study suggested that microfiltration layer-coated (alumina coating layer) silicon carbide support that underwent heat treatment at $1573 \mathrm{~K}$ for $1 \mathrm{~h}$ was a reliable appropriate platform for further additional ultrafiltration layer coating. ${ }^{28)}$ 


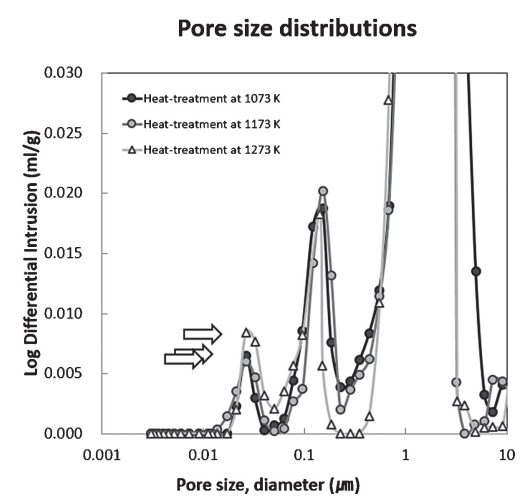

(a)

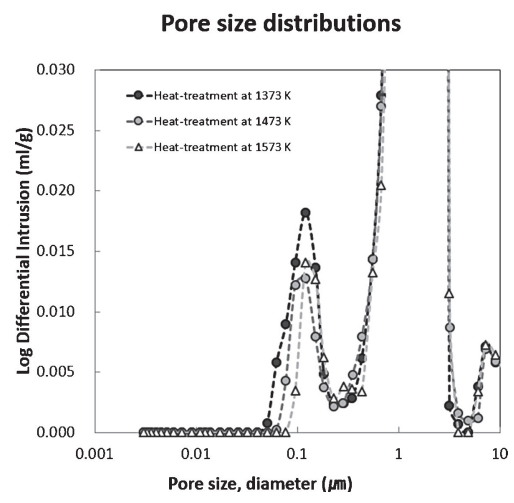

(b)

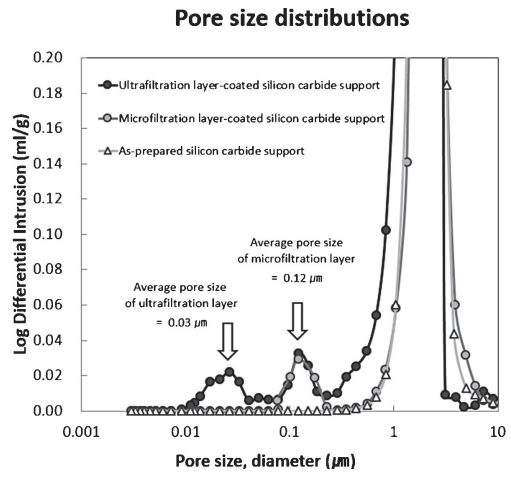

(c)

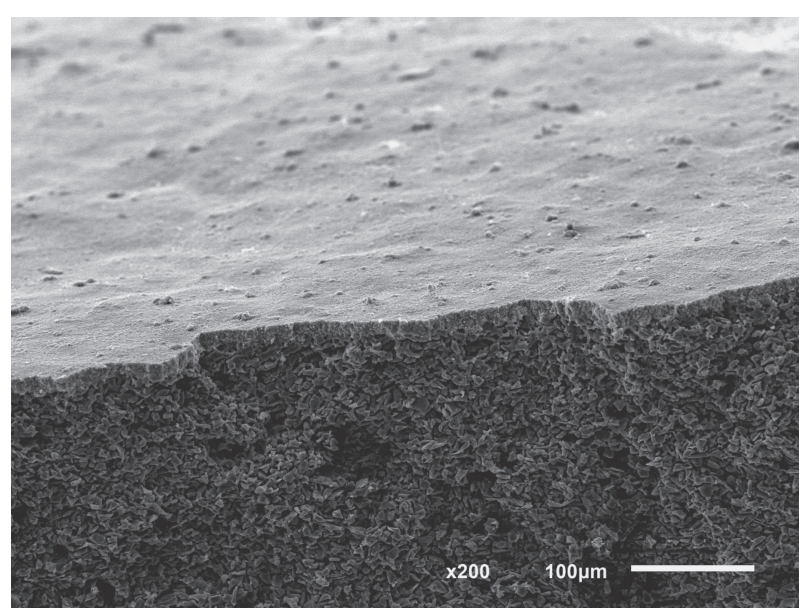

(d)

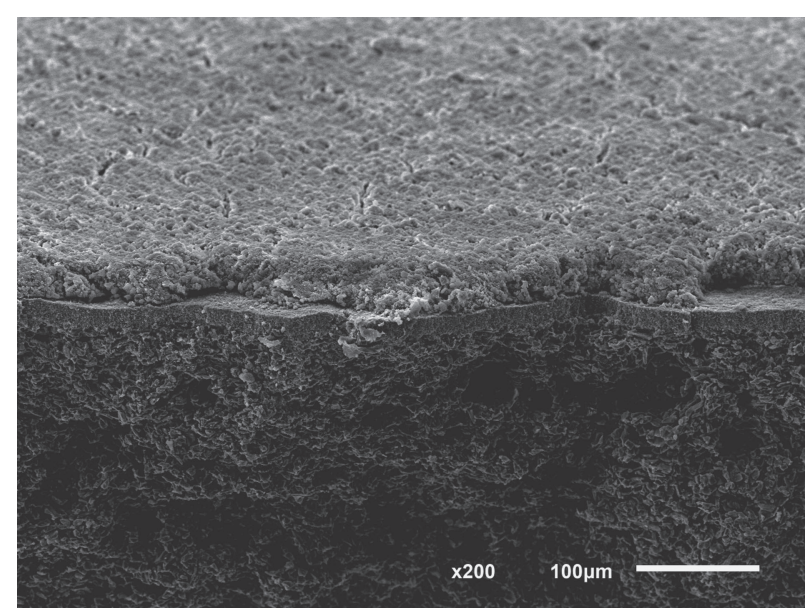

(e)

Fig. 2. Pore size distributions of silicon carbide supports which were microfiltration layer-coated and heat treated at $1573 \mathrm{~K}$ for $1 \mathrm{~h}$, and subsequently, ultrafiltration layer-coated and heat treated at (a) 1073 to $1273 \mathrm{~K}$ for $1 \mathrm{~h}$, and (b) 1373 to $1573 \mathrm{~K}$ for $1 \mathrm{~h}$. (c) Pore size distributions of the as-prepared silicon carbide support, and microfiltration and ultrafiltration layer coated-silicon carbide supports. Typical SEM images of the cross-sections of (d) microfiltration and (e) ultrafiltration layer-coated silicon carbide supports. Dip-coating conditions for microfiltration layer coating were the support dipping time was $10 \mathrm{~s}$, and the support withdrawal speed was $1 \mathrm{~mm} / \mathrm{s}$, and for ultrafiltration layer coating, the support dipping time was $5 \mathrm{~s}$, and the support withdrawal speed was $5 \mathrm{~mm} / \mathrm{s}$.

However, the temperature suitable for the fabrication of an effective ultrafiltration layer was not determined, because the average particle size of alumina for ultrafiltration was approximately $20 \%$ that of alumina used for microfiltration. Figure 2(a) depicts the pore size distribution of ultrafiltration layer-coated silicon carbide supports.

After heat treatment at $1073-1273 \mathrm{~K}$, the ultrafiltration layer-coated silicon carbide supports exhibit both ultrafiltration layer peaks around the average pore size of 0.03 $\mu \mathrm{m}$, and microfiltration layer peaks around the average pore size of $0.12 \mu \mathrm{m}$. However, after heat treatment at $1373-1573 \mathrm{~K}$, the ultrafiltration layer peaks around the average pore size $(0.03 \mu \mathrm{m})$ were completely diminished, and only the microfiltration layer peaks around the average pore size of $0.12 \mu \mathrm{m}$ were visible for the ultrafiltration layer-coated silicon carbide supports, as shown in Fig. 2(b).

This behavior can be explained as follows. The linear shrinkage rate of alumina particles began to increase abruptly at $1373 \mathrm{~K}$. This implied that alumina particles were undergoing the initial stage of sintering and experienced rapid inter-particle neck growth at this temperature. $^{42)}$ When the average particle size (for microfiltration) was in the sub-micron range, at $1573 \mathrm{~K}$, the alumina particles could maintain the inter-connected pore channels. However, the average particle size (for ultrafiltration) is approximately $50 \mathrm{~nm}$, and even at $1373 \mathrm{~K}$, alumina particles could not maintain the inter-connected pore channels because of the sintering driving force. It is well known that sintering strongly depends inversely on the particle size regardless of the sintering method or types of ceramic particles: silicon carbide, ${ }^{43), 44)}$ alumina, ${ }^{45)}$ gallium oxide, ${ }^{46)}$ and niobate. ${ }^{47)}$

Figure 2(c) shows the pore size distribution of the asprepared silicon carbide support, microfiltration, and ultrafiltration layer-coated silicon carbide supports. The ultrafiltration layer-coated silicon carbide support simultaneously exhibited both an ultrafiltration and a microfiltration layer peak around 0.03 and $0.12 \mu \mathrm{m}$, respectively. The microfiltration layer-coated silicon carbide support 
exhibited only a microfiltration layer peak around $0.12 \mu \mathrm{m}$, and the as-prepared silicon carbide support only exhibited its own support peak around $1.80 \mu \mathrm{m}$.

In addition to mercury porosimetry, the presence of an ultrafiltration layer on a silicon carbide support can be also confirmed by SEM analysis. Figure 2(d) shows the SEM cross-section of a microfiltration layer-coated silicon carbide support. This support was coated once using an alumina coating slurry for microfiltration (AKP-30, average particle size of $0.27 \mu \mathrm{m})$. The support shown in Fig. 2(e) was coated once using an alumina coating slurry for microfiltration (AKP-30, average particle size of 0.27 $\mu \mathrm{m})$ and subsequently coated using an alumina coating slurry for ultrafiltration (nano-alumina, average particle size of $50 \mathrm{~nm}$ ). There were few cracks, defects, or delamination imperfections between the microfiltration layer and the silicon carbide support. However, the ultrafiltration layer on the microfiltration layer had small cracks. This negatively influenced the pure water permeability of the ultrafiltration layer-coated silicon carbide support, which will be discussed later.

One of the authors' previous reports, ${ }^{28)}$ discussed possible problems regarding the coating slurry composition and dip-coating conditions that could occur prior to depositing the microfiltration (alumina coating) layer on the silicon carbide support. To alleviate the difficulties when that could occur during the measurement of the overall membrane properties, the compatibility between the alumina and silicon carbide-based support layers or the dip-coating conditions were investigated.

The authors attempted to optimize the dip-coating slurry composition by repetitive experiments, where the support dipping time was varied from 1 to $5 \mathrm{~s}$, and the support withdrawal speed from 5 to $10 \mathrm{~mm} / \mathrm{s}$. It became obvious that it was difficult to precisely control the support dipping time. In this study, an extruded silicon carbide support with flat sheet tube-type shape, width of $50 \mathrm{~mm}$, height of $4 \mathrm{~mm}$, and length of $200 \mathrm{~mm}$ was used. If the support withdrawal speed was set to $0.1 \mathrm{~mm} / \mathrm{s}$ and the support was attached lengthwise to the arm of the dip-coating machine, then the bottom of the support would be unintentionally dipped for $2000 \mathrm{~s}$ more than the top of the support layer. Therefore, even if a certain support dipping time could ensure a specific thickness of the coating layer, the process would generate a non-uniform lengthwise thickness distribution of the coating layer. Hence, for industrial applications, reducing the support dipping time and increasing the support withdrawal speed would be a reasonable approach.

The pore size distributions of the ultrafiltration layercoated silicon carbide supports (support size of $5 \mathrm{~cm}$ ) prepared by varying the support dipping time from 1 to $5 \mathrm{~s}$, and/or withdrawal speed from 5 to $10 \mathrm{~mm} / \mathrm{s}$, are shown in Fig. 3(a). The ultrafiltration layer-coated silicon carbide supports maintained both the ultrafiltration and the microfiltration layer peaks around 0.03 and $0.12 \mu \mathrm{m}$, respectively, regardless of the dip-coating conditions. The alumina coating thickness of the ultrafiltration layer-coated silicon carbide supports (support size of $5 \mathrm{~cm}$ ) could be controlled by varying the dip-coating conditions. The thickness of the ultrafiltration layer could be measured using SEM cross-section images, and cross-verified using mercury porosimetry (because the linear relationships between the log differential intrusion volume of mercury and the thickness of coating layer have already been thoroughly investigated ${ }^{28)}$ ).

However, when the silicon carbide support size increased from $5 \mathrm{~cm}$ (i.e., the dipping time of the support became more difficult to control due to the four-fold

\section{Pore size distributions}

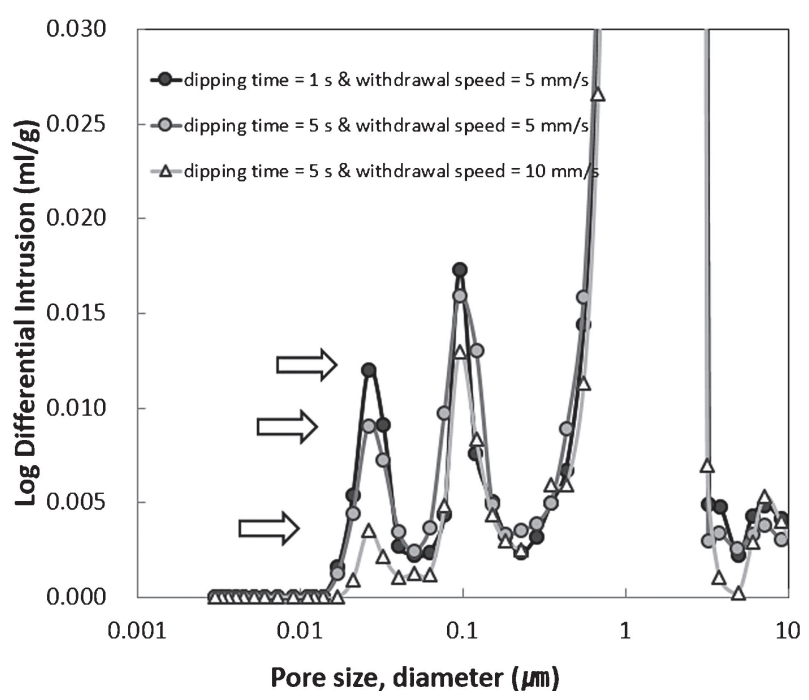

(a)

\section{Pore size distributions}

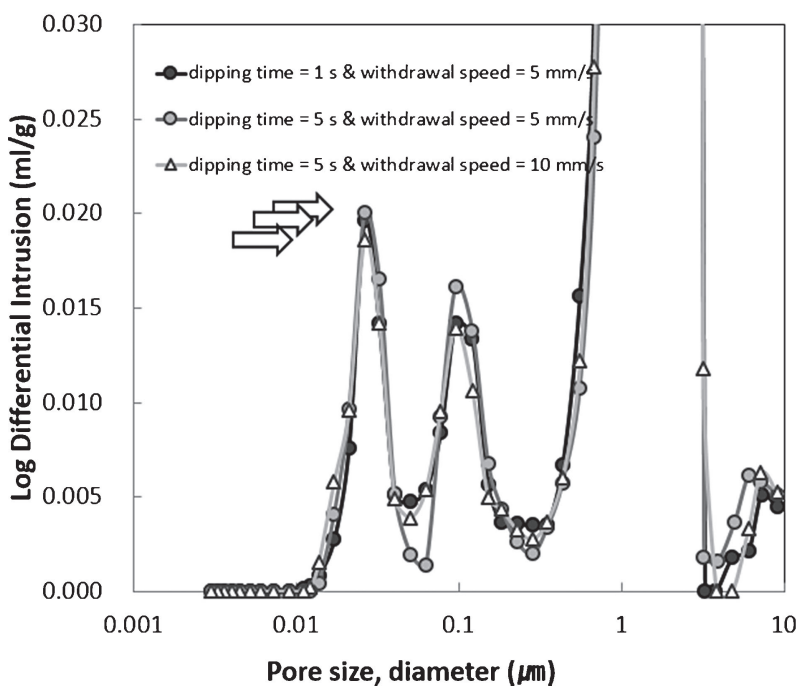

(b)

Fig. 3. Pore size distributions of ultrafiltration layer-coated silicon carbide supports with support sizes of (a) $5 \mathrm{~cm}$ and (b) $20 \mathrm{~cm}$ heat treated at $1273 \mathrm{~K}$ for $1 \mathrm{~h}$, varying the support dipping time from 1 to $5 \mathrm{~s}$ and support withdrawal speed from 5 to $10 \mathrm{~mm} / \mathrm{s}$. 


\section{Pore size distributions}

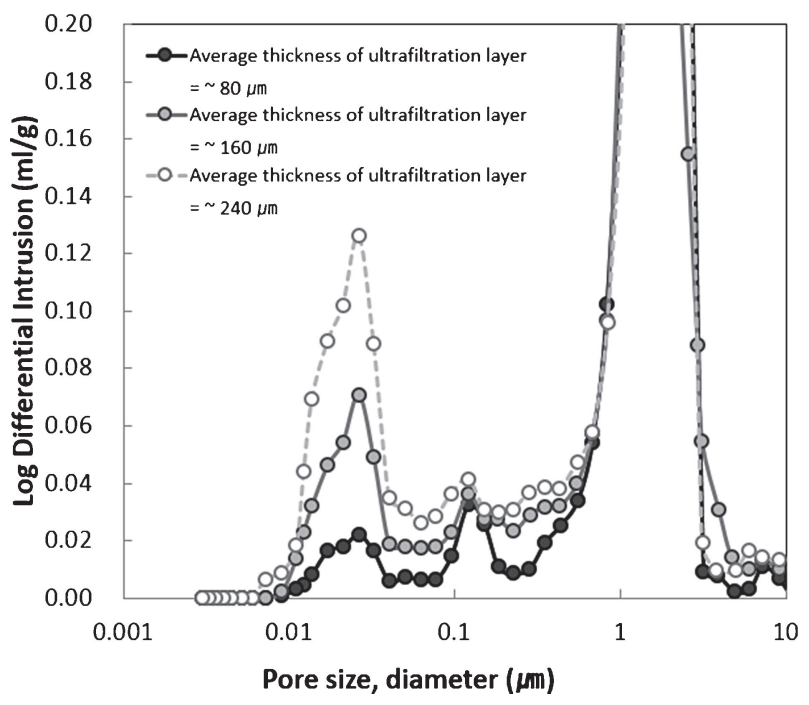

(a)

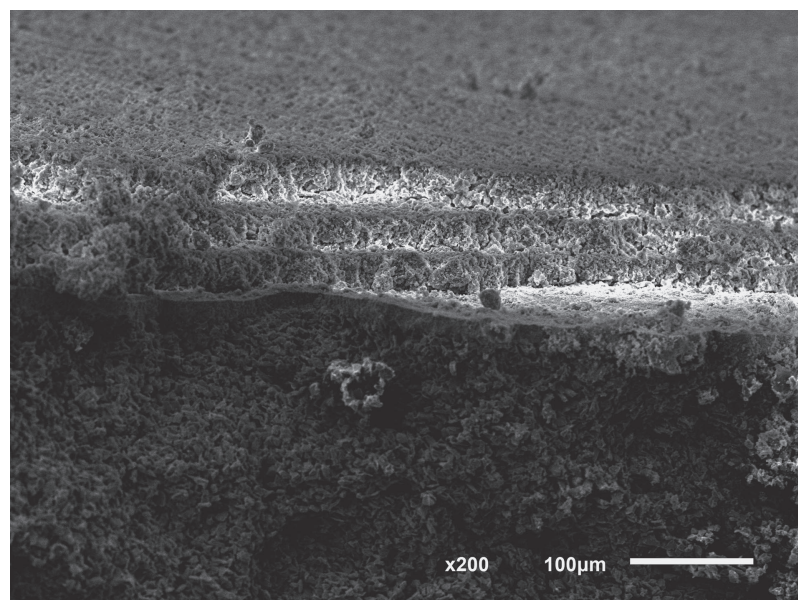

Pore size distributions

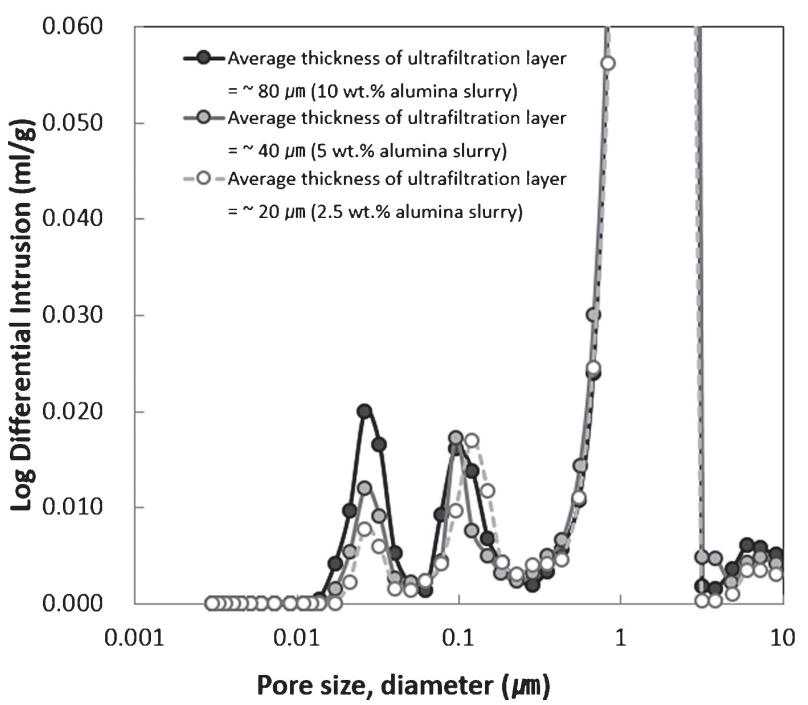

(b)

(c)

Fig. 4. Pore size distributions of ultrafiltration layer coated-silicon carbide supports heat treated at $1273 \mathrm{~K}$ for $1 \mathrm{~h}$ : (a) variation in the number of coating layers and (b) concentration of alumina in the coating slurry. (c) Typical SEM image of the cross-sections of an ultrafiltration layer-coated silicon carbide support which was coated three times and heat treated three times.

increase in support size), the thickness of the ultrafiltration layer could no longer be controlled using the dip-coating conditions. The pore size distributions of the ultrafiltration layer-coated silicon carbide supports (support size $=20$ $\mathrm{cm})$, prepared by varying the support dipping time from 1 to $5 \mathrm{~s}$ and/or withdrawal speed from 5 to $10 \mathrm{~mm} / \mathrm{s}$, are shown in Fig. 3(b). The thickness of the ultrafiltration layer of the ultrafiltration layer-coated silicon carbide supports (support size $=5 \mathrm{~cm}$ ) could not be controlled regardless of the dip-coating conditions. Hence, the thickness of the ultrafiltration layer of the ultrafiltration layer-coated silicon carbide support layer should be controlled by the other means, such as by increasing the number of alumina coating layers and/or reducing the concentration of alumina in the coating slurry. The authors tried to measure the thickness of ultrafiltration coating layer to discuss with more meaningful scientific data. However, it was difficult to obtain accurate thickness values because of the non-uniform coating thickness of some specimens. To avoid misunderstandings due to the non-accurate thickness value, the authors unfortunately discuss with the issues qualitatively.

First, the coating thickness of the ultrafiltration layer of the silicon carbide supports could be linearly increased by increasing the number of alumina coating layers. Figure 4(a) represents the pore size distributions of the ultrafiltration layer-coated silicon carbide supports with varying numbers of coating layers after heat treatment at $1273 \mathrm{~K}$ for $1 \mathrm{~h}$. The results suggested that the thickness of the ultrafiltration layer could be easily increased by increasing the number of coating layers without causing any loss in its industrial efficiency. This is meaningful 
because this does not always occur. For example, the thickness of the microfiltration layer of pyrophyllite supports did not increase linearly with the number of coatings. When pyrophyllite supports were coated four times, the thickness margin of increase in the coating layer after each coating step decreased significantly ${ }^{28)}$ due to poor permeability induced by poor pore-connectivity. Inherently, the poor pore-connectivity was affected by the plate-like shapes of the pyrophyllite particles. ${ }^{40)}$ The thickness of the ultrafiltration layer is very important to the operational life of a ceramic membrane because the flow rate of a commercial ceramic membrane can be easily renewed by brushing its outer surface with a stiff brush under running water. This process can be repeated until the thickness of the coating layer reaches a certain limit.

Second, the thickness of the ultrafiltration layer on the silicon carbide supports decreased linearly by decreasing the concentration of the alumina slurry. Figure 4(b) represents the pore size distributions of the ultrafiltration layercoated silicon carbide supports prepared using varying concentrations in the alumina coating slurry, after heat treatment at $1273 \mathrm{~K}$ for $1 \mathrm{~h}$. These silicon carbide supports were coated once with a coating containing 25,50 , and $100 \%$ of the concentration of alumina present in the slurry of the ultrafiltration layer-coated silicon carbide supports shown in Fig. 4(a). The results suggested that the thickness of the ultrafiltration layer could be easily reduced by simply reducing the concentration of alumina in the coating slurry. The thickness of the ultrafiltration layer is also very important especially, when the permeability is critical for the operational output.

Therefore, the combination of the increasing the number of alumina coating times and reducing the concentration of alumina in the coating slurry could help to easily achieve a specific ultrafiltration layer thickness. The support in Fig. 4(c) was coated three times, and the thickness of ultrafiltration layer was finally adjusted to $\sim 100 \mu \mathrm{m}$ by controlling the concentration of alumina in the coating slurry.

The organic binder (PVA in this study) is one of the inevitable additives during the alumina coating process, because it increases the viscosity of the alumina coating slurry and is also important in inhibiting crack formation after the dip coating process. ${ }^{42), 48)}$ However, adding an excessive amount of PVA could increase the surface roughness of the alumina coating layer as a side effect. By contrast, adding an insufficient amount of PVA could affect the formation of defects, cracks, or delamination imperfections between the alumina coating layer and silicon carbide support. The surface roughness of the microfiltration layer-coated silicon carbide supports was already investigated in one of the authors' previous studies ${ }^{28}$ ) because the surface roughness of the microfiltration layer could affect the deposition of an ultrafiltration layer, ${ }^{49)}$ although it did not affect the overall permeability or the average pore size.

In a previous study, when the surface of the microfiltration layer appeared rough due to the presence of hemispherical traces of agglomerated alumina particles, subjecting the sample to a ball-milling process was sufficient to eliminate the agglomerated alumina particles (AKP30, average particle size of $0.27 \mu \mathrm{m}$ ). However, during the preliminary experiments for this study, the abovementioned ball-milling process was not able to eliminate the agglomeration and settling of alumina particles (nanoalumina, average particle size of $50 \mathrm{~nm}$ ). The pore size distributions of ultrafiltration layer-coated silicon carbide supports prepared using repetitive un-optimized additives are shown in Fig. 5(a). Even though all of the processing conditions were unchanged, the reproducibility of the ultrafiltration layer-coated silicon carbide supports was quite low. The presence of the ultrafiltration peak from the ultrafiltration layer-coated silicon carbide support was random for each trial. It may be concluded that the low reproducibility was induced by a non-uniform ultrafiltration layer. Because of the un-optimized additives, the ultrafiltration layer was different for each sample that was cut for measuring the pore size distribution. Figure 5(b) shows the typical SEM cross-section image of a silicon carbide support when the ultrafiltration layer was not properly deposited. Only the microfiltration layer and the sparsely distributed agglomerated alumina particles, which were intended to form an ultrafiltration layer, could be identified in Fig. 5(b).

Therefore, it was necessary to adjust the optimum amounts of additives to obtain a uniform ultrafiltration layer. Once the amount of binder (PVA) was set, the authors also introduced a dispersant (ammonium chloride) to remove the undesirable agglomerated alumina particles and generate a homogenous alumina coating slurry. Figure 5(c) presents the pore size distributions of ultrafiltration layer-coated silicon carbide supports obtained under the same processing conditions as those shown in Fig. 5(a), except for the composition of additives. Unlike the result of the preliminary experiments, ultrafiltration peaks of the ultrafiltration layer-coated silicon carbide supports were detected because of the optimized amount of additives.

The effects of the ultrafiltration layer on the pure water permeability of silicon carbide supports were investigated using a dead-end microfiltration measurement system.

Figure 6 depicts the pure water permeability of the asprepared, microfiltration layer-coated, and ultrafiltration layer-coated silicon carbide supports (average pore sizes of $1.80,0.12$, and $0.03 \mu \mathrm{m}$, respectively). The pure water permeabilities of these supports were measured to be approximately $7.0 \times 10^{3}, 2.0 \times 10^{3}$, and $1.5 \times 10^{3}$ $\mathrm{L} \cdot \mathrm{m}^{-2} \cdot \mathrm{h}^{-1} \cdot \mathrm{bar}^{-1}$, respectively. Figure 6 indicates that the pure water permeability of the supports gradually decreased in over time. This trend was in good agreement with the pure water permeability curves of typical ultrafiltration membranes. ${ }^{50)}$ Furthermore, the pure water permeability of the ultrafiltration layer-coated silicon carbide support was lower than that of the microfiltration layercoated silicon carbide support. In general, the permeability of the coating layer governs the overall permeability of a membrane. Therefore, naturally the pure water permeabil- 


\section{Pore size distributions}

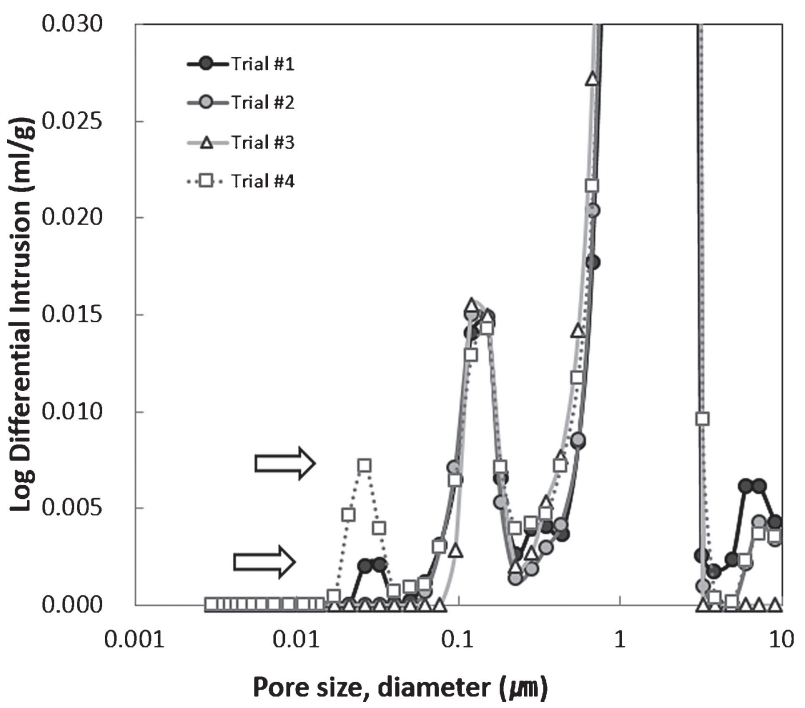

(a)

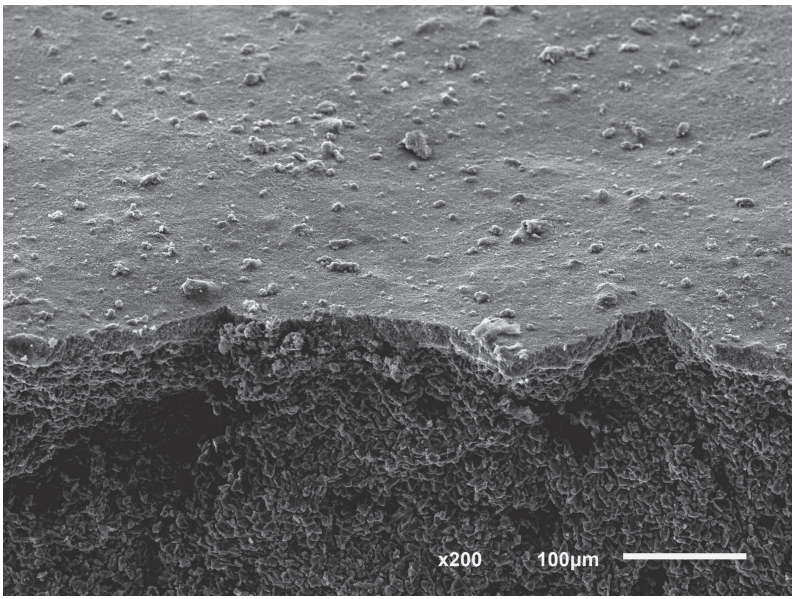

(b)

\section{Pore size distributions}

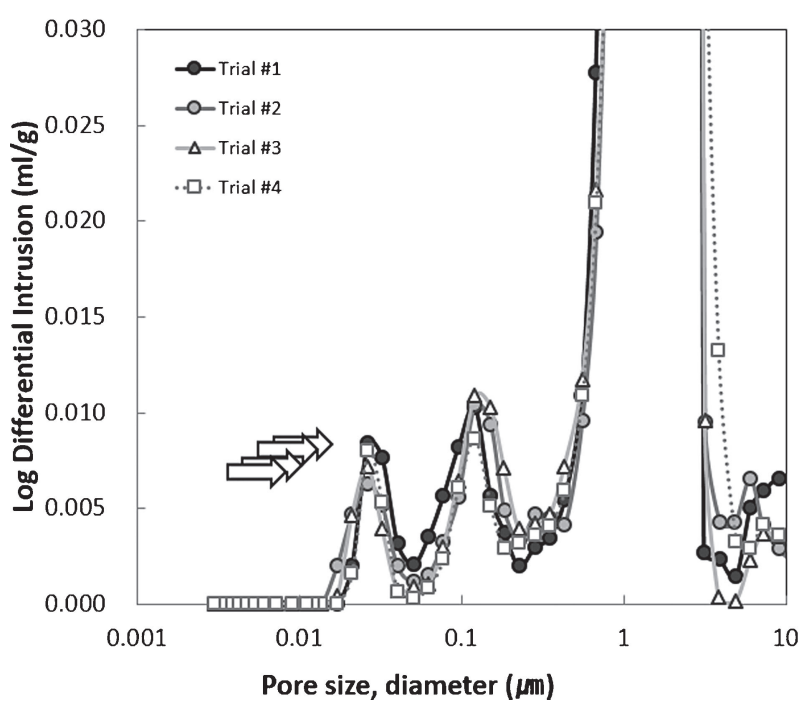

(c)

Fig. 5. (a) Pore size distributions of ultrafiltration layer coated-silicon carbide supports heat treated at $1273 \mathrm{~K}$ for $1 \mathrm{~h}$ (preliminary experiments), (b) typical SEM cross-section image of a silicon carbide support, when the ultrafiltration layer was not deposited well, and (c) pore size distributions of ultrafiltration layer coated-silicon carbide supports obtained using optimized additives and heat treated at $1273 \mathrm{~K}$ for $1 \mathrm{~h}$.

ity of the silicon carbide support decreased significantly after each deposition with of microfiltration and ultrafiltration layers.

According to the literature, the pure water permeability of silicon carbide supports (submicron average pore size) decreased significantly, from $1.0 \times 10^{3}$ to 0.5 $\mathrm{L} \cdot \mathrm{m}^{-2} \cdot \mathrm{h}^{-1} \cdot \mathrm{bar}^{-1}$, 39) after silicon carbide coating for ultrafiltration (average pore size of $0.005 \mu \mathrm{m}$ ). Moreover, the pure water permeability of silicon carbide supports (average pore size of $0.04 \mu \mathrm{m}$ ) decreased significantly, from $1.0 \times 10^{3}$ to $0.5 \mathrm{~L} \cdot \mathrm{m}^{-2} \cdot \mathrm{h}^{-1} \cdot \mathrm{bar}^{-1},{ }^{38)}$ after alumina coating for ultrafiltration (average pore size of $0.0055 \mu \mathrm{m}$ ). Lastly, the pure water permeability of alumina support (average pore size of $1.4 \mu \mathrm{m}$ ) decreased significantly, from 585.81 to $\left.252.51 \mathrm{~L} \cdot \mathrm{m}^{-2} \cdot \mathrm{h}^{-1} \cdot \mathrm{bar}^{-1}, 51\right)$ after alumina coating for ultrafiltration (average pore size of $0.1 \mu \mathrm{m}$ ). The data from this study as well as that from the literature, are in agreement with the theoretical analysis, wherein pure water permeability is inversely proportional to the thickness, porosity, and pore size of the coating layer. ${ }^{52)}$

In this study, if the ultrafiltration layer had been defectfree, the pure water permeability of the ultrafiltration layercoated silicon carbide supports would have been reduced further. However, the ultrafiltration layer had slight cracks and defects, as observed in Fig. 2(e). It should be mentioned that the deposition of a thin defect-free ultrafiltra- 


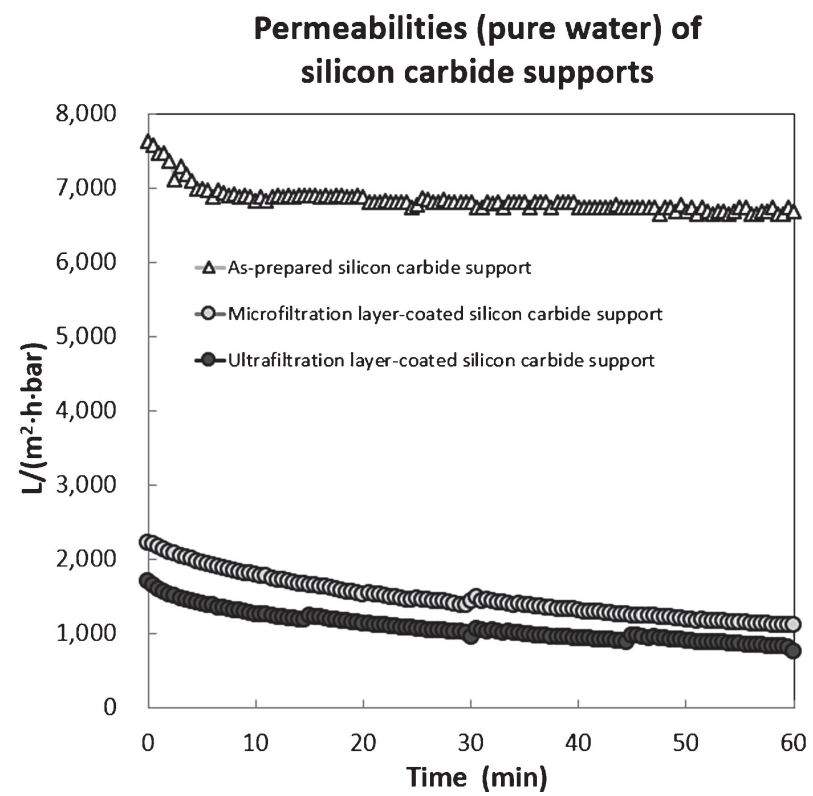

Fig. 6. Pure water permeabilities of an as-prepared silicon carbide support, a microfiltration and an ultrafiltration layercoated silicon carbide support, measured using the dead-end microfiltration system.

tion layer on commercial silicon carbide supports is very difficult due to their surface coarseness and heterogeneity. ${ }^{39)}$ Moreover the ultrafiltration layer in this study simply utilized commercial nano-sized alumina particles to avoid the cumbersome and difficult sol-gel process for preparing nano-sized alumina particles.

Unfortunately, the molecular weight cut-off values of the ultrafiltration layer-coated silicon carbide supports were not tested since this was the initial stage of research and the ultrafiltration layer being imperfect. These properties will be investigated in a future study after achieving a defect-free ultrafiltration layer. However, this study found that ultrafiltration layer-coated silicon carbide supports are feasible candidates for ultrafiltration, because they have favorable membrane properties and low sintering temperatures, can be manufactured using simple processing steps, and require inexpensive raw materials.

\section{Conclusions}

In this study, ultrafiltration layer-coated silicon carbide supports were fabricated using a dip-coating method and subsequent heat treatment. The average pore size of a silicon carbide support $(1.80 \mu \mathrm{m})$ was significantly reduced to $0.12 \mu \mathrm{m}$ after the deposition of a microfiltration layer, and again to $0.03 \mu \mathrm{m}$ after the subsequent deposition of an ultrafiltration layer. The coating thickness of the ultrafiltration layer was controlled by varying the number of coatings or the concentration of alumina in the coating slurry. The temperature of the heat-treatment, dip-coating conditions, and slurry compositions of the ultrafiltration layer were optimized, which led to the resulting ultrafiltration layer-coated silicon carbide supports being potentially suitable for nanofiltration. The feasibility of silicon carbide supports for nanofiltration will be an interesting topic for future studies.

The pure water permeability of the ultrafiltration layercoated silicon carbide support was maintained during the filtration test. The pure water permeability of the silicon carbide supports decreased as the microfiltration and ultrafiltration layer were sequentially deposited. Considering the discussed membrane properties, ultrafiltration layercoated silicon carbide supports can be appropriately used for ultrafiltration as low-cost substitutes for conventional alumina-based supports.

\section{References}

1) A. R. Studart, U. T. Gonzenbach, E. Tervoort and L. J. Gauckler, J. Am. Ceram. Soc., 89, 1771-1789 (2006).

2) U. T. Gonzenbach, A. R. Studart, D. Steinlin, E. Tervoort and L. J. Gauckler, J. Am. Ceram. Soc., 90, 3407-3414 (2007).

3) Z.-Y. Deng, J. M. F. Ferreira, Y. Tanaka and Y. Isoda, Acta. Mater., 55, 3663-3669 (2007).

4) F. Raether and M. Iuga, J. Eur. Ceram. Soc., 26, 26532667 (2006).

5) Z. Hou, F. Ye, L. Liu, Q. Liu and H. Zhang, Ceram. Int., 39, 1075-1079 (2013).

6) M. Wegmann, B. Michen and T. Graule, J. Eur. Ceram. Soc., 28, 1603-1612 (2008).

7) S. S. Madaeni, H. Ahmadi Monfared, V. Vatanpour, A. Arabi Shamsabadi, E. Salehi, P. Daraei, S. Laki and S. M. Khatami, Desalination, 293, 87-93 (2012).

8) M. Dilaver, S. M. Hocaoğlu, G. Soydemir, M. Dursun, B. Keskinler, İ. Koyuncu and M. Ağtaș, J. Clean. Prod., 171, 220-233 (2018).

9) S. Barredo-Damas, M. I. Alcaina-Miranda, A. Bes-Piá, M. I. Iborra-Clar, A. Iborra-Clar and J. A. MendozaRoca, Desalination, 250, 623-628 (2010).

10) B. K. Nandi, B. Das, R. Uppaluri and M. K. Purkait, J. Food Eng., 95, 597-605 (2009).

11) M. Ebrahimi, S. Kerker, O. Schmitz, A. A. Schmidt and P. Czermak, Separ. Sci. Technol., 53, 349-363 (2018).

12) J. H. Ha, B. Bae and I. H. Song, Adv. Appl. Ceram., 114, 156-163 (2015).

13) J. H. Ha, D. W. Jung and I. H. Song, Ceram. Int., 40, 12961-12967 (2014).

14) J. H. Ha, E. Oh, R. Ahmad and I. H. Song, Ceram. Int., 39, 3881-3884 (2013).

15) J. H. Ha, E. Oh, R. Ahmad and I. H. Song, J. Ceram. Soc. Jpn., 121, 426-429 (2013).

16) J. H. Ha, E. Oh, B. Bae and I. H. Song, Ceram. Int., 39, 8955-8962 (2013).

17) J. H. Ha, E. Oh and I. H. Song, Ceram. Int., 39, 76417648 (2013).

18) J. H. Ha, E. Oh and I. H. Song, J. Ceram. Soc. Jpn., 121, 940-945 (2013).

19) J. H. Ha, E. Oh and I. H. Song, Ceram. Int., 40, 22212227 (2014).

20) J. H. Ha, Y. H. Park and I. H. Song, J. Ceram. Soc. Jpn., 122, 714-718 (2014)

21) J. H. Ha, Y. H. Park and I. H. Song, Arch. Metall. Mater., 60, 1175-1178 (2015).

22) J.-H. Ha, S. Z. Abbas Bukhari, J. Lee, I.-H. Song and C. Park, Ceram. Int., 42, 13796-13804 (2016).

23) J.-H. Ha, J. Lee and I.-H. Song, J. Ceram. Soc. Jpn., 
123, 656-661 (2015).

24) I. H. Song, E. J. Lee, H. D. Kim, Y. W. Kim and D. W. Yun, J. Korean Ceram. Soc., 48, 404-411 (2011).

25) J.-H. Ha, S. Lee, S. Z. Abbas Bukhari, J. Lee and I.-H. Song, Ceram. Int., 43, 1536-1542 (2017).

26) J. H. Ha, S. Z. A. Bukhari, J. Lee, I. H. Song and S. H. Lee, J. Ceram. Soc. Jpn., 123, 1043-1050 (2015).

27) J.-H. Ha, J. Lee, I.-H. Song and S.-H. Lee, Ceram. Int., 41, 9542-9548 (2015).

28) J.-H. Ha, S. Lee, S. Z. Abbas Bukhari, J. R. Choi, J. Lee, I.-H. Song, S. J. Lee and J. Choi, Ceram. Int., 43, 9481-9487 (2017).

29) S. Z. A. Bukhari, J.-H. Ha, J. Lee and I.-H. Song, Ceram. Int., 43, 7736-7742 (2017).

30) S. Z. A. Bukhari, J. H. Ha, J. Lee and I. H. Song, J. Eur. Ceram. Soc., 38, 1711-1719 (2018).

31) B. Hofs, J. Ogier, D. Vries, E. F. Beerendonk and E. R. Cornelissen, Sep. Purif. Technol., 79, 365-374 (2011).

32) M. C. Fraga, S. Sanches, V. J. Pereira, J. G. Crespo, L. Yuan, J. Marcher, M. M. de Yuso, E. RodríguezCastellón and J. Benavente, J. Eur. Ceram. Soc., 37, 899-905 (2017).

33) C.-Y. Bai, X.-Y. Deng, J.-B. Li, Y.-N. Jing, W.-K. Jiang, Z.-M. Liu and Y. Li, Ceram. Int., 40, 6225-6231 (2014).

34) B. Skibinski, P. Müller and W. Uhl, J. Membrane Sci., 499, 92-104 (2016).

35) W. Shi, B. Liu, X. Deng, J. Li and Y. Yang, J. Eur. Ceram. Soc., 36, 3465-3472 (2016).

36) S. Z. A. Bukhari, J.-H. Ha, J. Lee and I.-H. Song, J. Eur. Ceram. Soc., 38, 1711-1719 (2017).

37) F. Sandra, A. Ballestero, V. L. Nguyen, M. N. Tsampas, P. Vernoux, C. Balan, Y. Iwamoto, U. B. Demirci, P. Miele and S. Bernard, J. Membrane Sci., 501, 79-92
(2016).

38) M. Facciotti, V. Boffa, G. Magnacca, L. B. Jørgensen, P. K. Kristensen, A. Farsi, K. König, M. L. Christensen and Y. Yue, Ceram. Int., 40, 3277-3285 (2014).

39) K. König, V. Boffa, B. Buchbjerg, A. Farsi, M. L. Christensen, G. Magnacca and Y. Yue, J. Membrane Sci., 472, 232-240 (2014).

40) J. H. Ha, S. Z. Abbas Bukhari, J. Lee and I. H. Song, Ceram. Int., 41, 13372-13380 (2015).

41) Y. Gu and G. Meng, J. Eur. Ceram. Soc., 19, 1961-1966 (1999).

42) J. Zhu, Y. Fan and N. Xu, J. Membrane Sci., 367, 14-20 (2011).

43) M. Shahedi Asl, Z. Ahmadi, S. Parvizi, Z. Balak and I. Farahbakhsh, Ceram. Int., 43, 13924-13931 (2017).

44) B. Matović, D. Bučevac, V. Urbanović, N. Stanković, N. Daneu, T. Volkov-Husović and B. Babic, J. Eur. Ceram. Soc., 36, 3005-3010 (2016).

45) W. Cao, X. Mao, Y. Yuan, L. Li, L. Zhao and J. Li, J. Eur. Ceram. Soc., 37, 4005-4013 (2017).

46) J.-J. Shan, C.-H. Li, J.-M. Wu, J.-A. Liu, A.-N. Chen and Y.-S. Shi, Ceram. Int., 43, 16843-16850 (2017).

47) L.-Q. Cheng, J.-J. Zhou, K. Wang, J.-F. Li and Q.-M. Wang, J. Mater. Sci., 47, 6908-6914 (2012).

48) W. Qin, K. Guan, B. Lei, Y. Liu, C. Peng and J. Wu, J. Membrane Sci., 490, 160-168 (2015).

49) H. Qi, S. Niu, X. Jiang and N. Xu, Ceram. Int., 39, 2463-2471 (2013).

50) L. Song, J. Membrane Sci., 139, 183-200 (1998).

51) K. A. Manjumol, P. Shajesh, K. V. Baiju and K. G. K. Warrier, J. Membrane Sci., 375, 134-140 (2011).

52) W. Li, W. Xing and N. Xu, Desalination, 192, 340-345 (2006) 